$9-2020$

\title{
Occupational Therapy and Accessibility in the Outdoors and Summer Camps
}

David M. Lewis

University of St. Augustine for Health Sciences

DOI: https://doi.org/10.46409/sr.IMPZ5077

Follow this and additional works at: https://soar.usa.edu/capstones

Part of the Occupational Therapy Commons

\section{Recommended Citation}

Lewis, D. M. (2020). Occupational Therapy and Accessibility in the Outdoors and Summer Camps. [Doctoral project, University of St Augustine for Health Sciences]. SOAR @ USA: Student Capstone Projects Collection. https://doi.org/10.46409/sr.IMPZ5077

This Capstone is brought to you for free and open access by the Student Research at SOAR @ USA. It has been accepted for inclusion in Student Capstone Projects by an authorized administrator of SOAR @ USA. For more information, please contact soar@usa.edu, erobinson@usa.edu. 
Occupational Therapy and Accessibility in the Outdoors and Summer Camps

\author{
David M. Lewis \\ Department of Occupational Therapy, University of St. Augustine for Health Sciences
}

\begin{abstract}
A Capstone Presented in Partial Fulfillment of the Requirement for the Degree of DOCTOR OF OCCUPATIONAL THERAPY

University of St. Augustine for Health Sciences
\end{abstract}

August, 2020 


\title{
Occupational Therapy and Accessibility in the Outdoors and Summer Camps
}

\author{
David M. Lewis
}

Department of Occupational Therapy, University of St. Augustine for Health Sciences

has been approved

August, 2020

APPROVED:

Susan MacDermott, OTD, OTR/L, Doctoral Coordinator

Becki Cohill, OTD, OTR/L, Doctoral Coordinator

Erin Schwier, EdD, OTD, OTR/L, Program Director

ACCEPTED AND SIGNED:

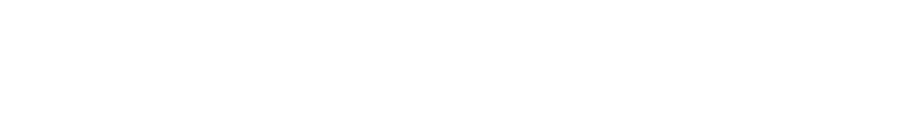

Susan MacDermott, OTD, OTR/L, Doctoral Coordinator

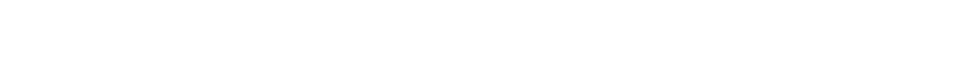

Becki Cohill, OTD, OTR/L, Doctoral Coordinator

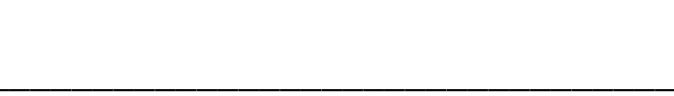

Erin Schwier, EdD, OTD, OTR/L, Program Director 


\section{Table of Contents}

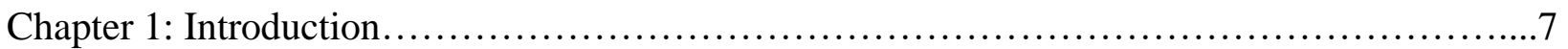

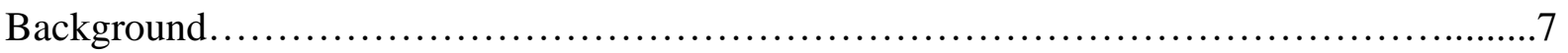

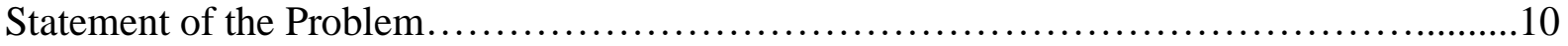

Purpose Statement........................................................... 10

Rationale for the Proposed Project......................................................

Significance of the Proposed Project............................................. 13

Preliminary Project Objectives.................................................14

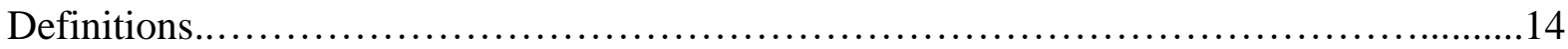

Assumptions, Limitations, Delimitations........................................ 15

Chapter 2: Literature Review.................................................... 16

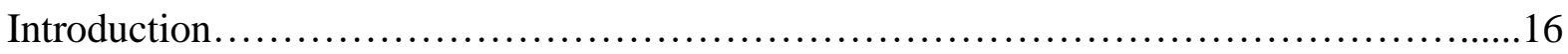

Positive Youth Development (PYD) and Camp Experiences............................17

Quality of Life and Social Participation........................................... 18

Identity, Independence, and Leadership.........................................19

Camp Experiences for Children with Disabilities ....................................20

Inclusion in Camps and Outdoor Recreation....................................... 21

Physical Environments and Occupational Performance...................................

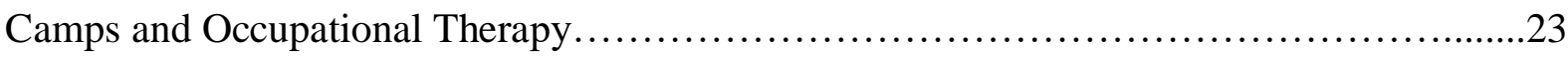

Literature Review Conclusion.................................................24

Chapter 3: Methods.................................................................

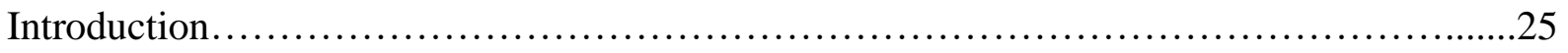

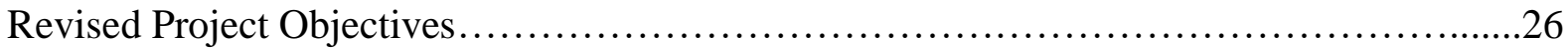




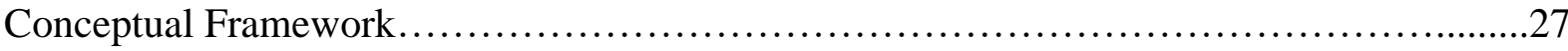

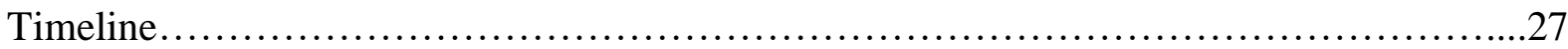

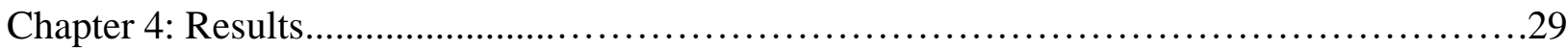

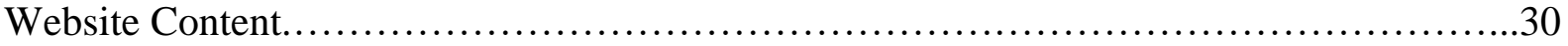

Home and About Pages...................................................................................... 30

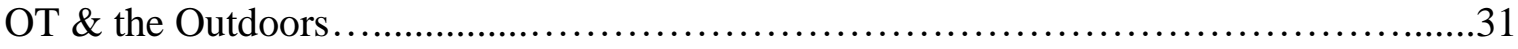

Inclusion \& Accessibility Organizations......................................... 32

Activity Adaptations \& Adaptive Equipment.....................................33

Accessibility Standards \& Guidelines...........................................34

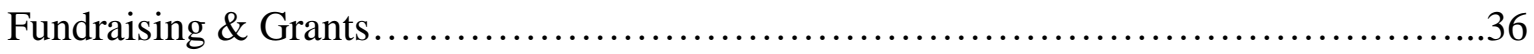

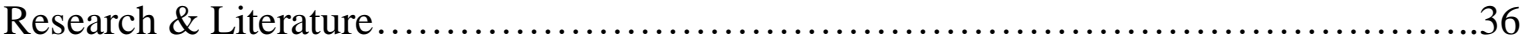

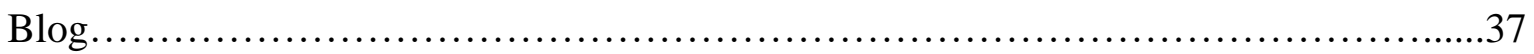

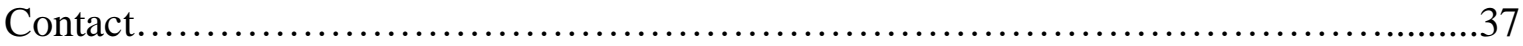

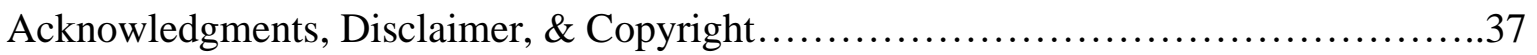

Results Conclusion........................................................... 38

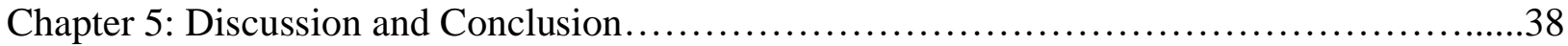

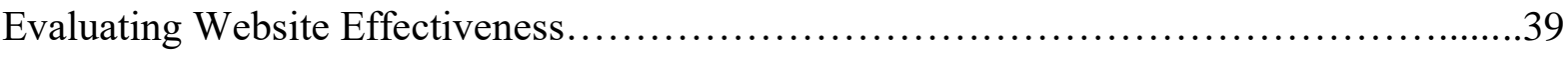

Envisioned Next Steps..........................................................40

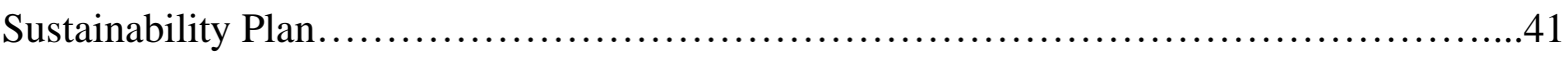

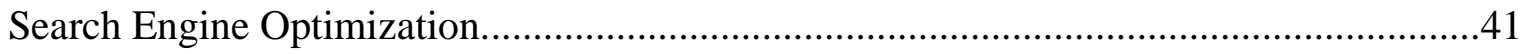

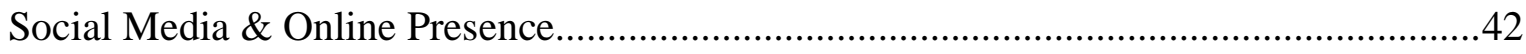

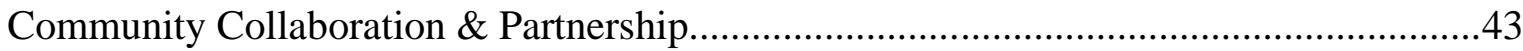


Professional Development \& Sharing...................................................................43

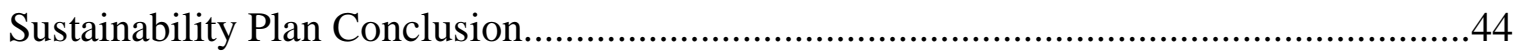

Occupational Therapy Impact.............................................44

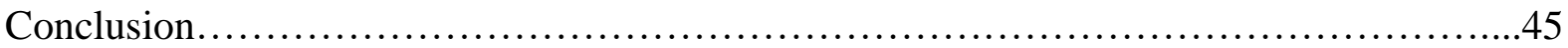

References......................................................................... 47

Appendix A - Logic Model........................................................54 
Copyright (C) David M. Lewis, 2020 all rights reserved 


\section{Occupational Therapy and Accessibility in the Outdoors and Summer Camps}

\section{Chapter 1: Introduction}

The purpose of this paper is to utilize an occupational therapy approach to further understand how to promote inclusion and accessibility practices in outdoor recreation and camp settings. The vision is to further support occupational performance and participation for individuals of all abilities in these settings.

\section{Background}

The development of youth and adolescents is multifaceted and composed of several factors that can promote or hinder adequate acquisition of skills. The opportunities granted for socializing with peers, building team and leadership skills, creating positive identities, and facilitating exploration of outdoor and natural environments occur in a variety of settings. Multiple studies indicate the positive impacts that attending summer camps have on youth and adolescents (Buskirk-Cohen, 2015; Dworken, 2001; Halsall et al., 2016; Hanscom, 2014; Henderson et al., 2007; Snider \& Farmer, 2017; Thurber et al., 2007; Zarrett et al., 2013). Research points to beneficial outcomes and positive reflection occurring during the camp experience, in the months after, and as adults later in life (Halsall et al., 2016; Snider \& Farmer, 2017). The characteristics, experiences, and skills that youth and adolescents develop through outdoor recreation and at summer camps can be generalizable and transferable to other roles and contexts of life. Identified areas of outcome findings include positive identity, social skills, social competency, self-esteem, positive values and spirituality, thinking, and physical skills (BuskirkCohen, 2015; Halsall et al., 2016; Snider \& Farmer, 2017). Within these categories, constructs such as independence, leadership, making friends, social comfort, peer relationships, positive values, adventure and exploration, and environmental awareness are identified as correlating 
positively with campers' experiences (Buskirk-Cohen, 2015; Garst et al., 2011; Halsall et al., 2016; Henderson et al., 2007; Henderson, 2012; Snider \& Farmer, 2017). The opportunities presented by outdoor recreation and the summer camp experience inherently address important areas of youth and adolescent development in the contexts of leisure, social participation, and engagement.

While the beneficial outcomes of the outdoors and summer camps are well documented, there remains a need to understand how facilitators and barriers to youth and adolescents with disabilities impact their access and participation in outdoor recreation and summer camp programs. Several studies have looked at the experiences of children with disabilities at summer camps, from a variety of different lenses (Bandino et al., 2014; Clark \& Nwokah, 2011; Devine et al., 2015; Goodwin et al., 2011; McCarthy, 2015; Moola et al., 2014; Provident \& Colmer, 2011; Walker et al., 2010). The reoccurring benefits of the outdoors and summer camp experiences have been established for both children and adolescents with and without disabilities. However, the experience of individuals with disabilities is altered by their ability to participate, engage, and access the different aspects of outdoor recreation and summer camp programs. Largely influential components of the experience of individuals with disabilities are environment and context (Cosco \& Moore, 2009; Furtado et al., 2017; Goodwin et al., 2011; Hanscom, 2014; Marshall et al., 2016; Papaioannou et al., 2013; Pfeiffer et al., 2017; Walker et al., 2010). Several studies have discussed the role of disability-specific residential camps in providing environments and contexts of social acceptance for these populations (Bandino et al., 2014; Clark \& Nwokah, 2011; Devine et al., 2015; Flynn et al., 2019). Furthermore, Boyd et al. (2008) identified a lack of research analyzing the opportunities for children with and without disabilities to interact outside of school settings, and subsequently researched the effects of a 
camp program to address this need.

At the philosophical and foundational basis of occupational therapy (OT) is engagement and participation in activities that individuals find meaningful and purposeful. With this understanding, the role of OT at summer camps and in developing outdoor recreation and camp programs becomes apparent. As mentioned, youth and adolescent development is positively impacted across many domains when this population is granted opportunities to engage and participate in the outdoors and camp. The facilitators and barriers that exist for engagement and participation in the population of youth and adolescents presents an optimal opportunity for occupational therapists to become involved. The current involvement of OT in the outdoors and summer camp programs, while growing, has been rather limited in literature. Angela Hanscom is a pediatric occupational therapist who developed TimberNook, a nature camp developed from OT principles. Hanscom (2014) discusses how OT principles can help promote youth development through outdoor experiences. Additional research into the role of OT at summer camps deals more with sensory integration and therapeutic horseback riding (Candler, 2003). While there also continues to be more involvement of occupational therapists in outdoor recreation and in summer camp programming, the field of OT would benefit from a further understanding into this role.

The Occupational Therapy Practice Framework: Domain \& Process has identified five OT intervention approaches (American Occupational Therapy Association [AOTA], 2017). The create/promote approach is most appropriate when considering outdoor recreation and summer camp programs. By creating and promoting experiences for children of all abilities to participate and engage in the programs and activities through considerations and recommendations of adaptations, grading, and design, there are opportunities to enhance youth and adolescent 
development. A specific role of the occupational therapist is in conducting a needs assessment, which should be done for outdoor recreation activities, camp programs and facilities. Potential principles and concepts to consider within this needs assessment are universal design, activity analysis, and environmental supports/barriers. With these considerations, an occupational therapy approach is unique in addressing the needs of outdoor recreation and summer camp programs for youth and adolescents of all abilities.

\section{Statement of the Problem}

There remains a need in understanding and developing how outdoor recreation and summer camps can further promote inclusion and accessibility for individuals of all abilities. The potential benefits for both children with disabilities and children without disabilities include social acceptance and competence, improved self-esteem, and relationship and role formation. Currently, OT in the outdoors and summer camps has a growing but limited role in the development of outdoor recreation and camp programs. Furthermore, the research concerning the role of OT and the effectiveness of OT in the outdoors and summer camps is even more limited. The understanding of how occupational therapists can collaborate with children of all abilities, parents, and recreation and camp staff to further promote occupational performance within the context and environment of the outdoors and summer camp adds inherent value to this area of practice. The adaptation of programs, environments, and activities in the outdoors and at summer camps can be facilitated through an occupational therapy scope of practice. This project presents a substantial opportunity when further considering how OT-focused adaptations can address engagement and participation in these settings.

\section{Purpose Statement}

One purpose of this capstone is to determine, propose, implement, and analyze potential 
adaptations to outdoor recreation and summer camps from an OT perspective. Another purpose is to assess the role of occupational therapy in the outdoors and at summer camps. The focus of this project is on the potential role of OT to adapt a current residential summer camp to create, promote, and enhance programs for individuals of all abilities.

\section{Rationale for Proposed Project}

\section{Ecology of Human Performance Model}

The understanding and implementation of occupational therapy approaches is done through the use of applied theories, models, and frameworks. The Ecology of Human Performance (EHP) model is a practice designed to be considered across multiple disciplines and specifically includes educators, rehabilitation specialists, and occupational therapists (Dunn, et al., 1994). Outdoor recreation and camp programs typically include outdoor educators and camp counselors as staff, making this model's multidisciplinary design appropriate for those most involved in the programs and activities of a camp. The focus of this model is on the transaction between individuals and the contexts within which occupational performance occurs for tasks. The EHP model understands that environment and context are inherently linked as facilitators or barriers to human behavior and task performance (Dunn et al., 1994). The definition of environment in the EHP model includes physical, social, and cultural aspects. With consideration to outdoor recreation and summer camp, each of these environmental aspects is important to analyze and discuss when developing an OT approach to better enhance opportunities for occupational performance. OT focused program adaptation can specifically target and maximize opportunities for campers to benefit across these environmental aspects. Additionally, the EHP model discusses the importance of temporal aspects of context (Dunn et al., 1994). Temporal context becomes more apparent when considering the previously discussed importance of 
development during youth and adolescence. At these ages, individuals benefit immensely when opportunities that promote social, physical, cognitive, and emotional growth are granted in the outdoors and camp setting (Buskirk-Cohen, 2015; Dworken, 2001; Halsall et al., 2016; Hanscom, 2014; Henderson et al., 2007; Snider \& Farmer, 2017; Thurber et al., 2007; Zarrett et al., 2013). These benefits extend far beyond the temporal timeframe of the actual camp experience, and echo throughout individuals' lives into adulthood (Halsall et al., 2016; Snider \& Farmer, 2017). Furthermore, the context and environment of the outdoors and camp itself is valuable and pertinent to the thorough understanding of occupational performance, as understood by the principles and foundations of the EHP model. By understanding and analyzing these components of context, it is easier to develop and understand the variables that either support or hinder occupational performance.

The EHP model has been so fundamental to occupational therapy that intervention approaches outlined throughout EHP have been adopted into the OT Practice Framework (Cole \& Tufano, 2008). As previously discussed, the create/promote approach to intervention provides an appropriate lens for applying OT skills within the context of the outdoors and summer camps. At the foundations of the create/promote approach are the ideas that occupational performance can be enriched, promoted, and supported through adaptable measures that benefit and include persons of all abilities in society (AOTA, 2017; Cole \& Tufano, 2008). This capstone project aims to apply this create/promote approach to provide recommendations that enrich outdoor recreation and summer camp programs. The understanding and rationale is that by engaging in OT interventions that advocate and promote equal rights, access, and fairness for all persons, the betterment of society as a whole is enhanced (Cole \& Tufano, 2008). The creation of contexts that support optimal performance are goals addressed by both the EHP model and through the 
create/promote approach to OT intervention. By utilizing an OT lens in the outdoors and summer camps, these aspects of OT provide an opportunity to enhance the participation, experience, and accessibility of the programs. These aspects of OT practice are beneficial and valuable in considering the needs of outdoor recreation and summer camps for persons of all abilities.

\section{Significance of the Proposed Project}

The benefits of participation in outdoor recreation and summer camps for youth and adolescence include socializing with peers, building team and leadership skills, creating positive identities, and facilitating exploration of natural environments (Buskirk-Cohen, 2015; Dworken, 2001; Halsall et al. 2016; Hanscom, 2014; Henderson et al., 2007; Snider \& Farmer, 2017;

Thurber et al., 2007; Zarrett et al., 2013). Additionally, the value of these types of programs for individuals with disabilities is supported by research looking at social competency, self-esteem, and relationship building among many other positive outcomes (Bandino et al., 2014; Clark \& Nwokah, 2011; Devine et al., 2015; Goodwin et al., 2011; McCarthy, 2015; Moola et al., 2014; Provident \& Colmer, 2011; Walker et al., 2010). However, there remains a need to understand facilitators and barriers to access, engagement, and performance. By approaching this problem through an occupational therapy lens and by using the identified EHP approach and practice framework previously discussed, both the population of persons with all abilities can benefit as can the overall programs and facilities. Through a needs assessment, research review, activity analysis, and collaborative efforts there are several potential adaptations, recommendations, and considerations that an OT perspective can provide. Ultimately the proposed project hopes to develop the understanding of the role of OT in the outdoors and summer camps. These potential roles include reducing barriers for populations with disabilities, encouraging facilitators of occupational performance, advocating for environments that are inclusive for persons of all 
abilities, educating and consulting with staff, and adapting aspects of a camp program to holistically address and increase occupational performances of youth and adolescence.

\section{Preliminary Project Objectives}

I. To further review successful approaches to inclusion and adaptations that have benefited similar activities and programs.

II. To assess the occupational needs of youth and adolescents in residential summer camp settings through observations and focus groups.

III. To conduct activity analyses of the programs and activities at the residential summer camp and determine what activities and programs would benefit from recommendations and considerations of inclusion and adaptation.

IV. To consult with the program director and provide finalized recommendations and training for the residential summer camp.

V. To implement agreed upon recommendations at the residential summer camp.

VI. To assess the impact of the recommendations at the residential summer camp.

VII. To generalize the effective recommendations to other similar programs and settings that could benefit from this knowledge and understanding.

VIII. To define and further advocate for the role of OT at residential summer camps.

\section{Definitions}

Residential Summer Camp is defined as a supervised, sleepaway program for children and teenagers that offers various experiences including but not limited to rock climbing, swimming, canoeing, high ropes, horseback riding, arts and crafts, hiking, survival skills, and teamwork activities (Summer Camp, 2019).

Positive Youth Development (PYD) in this project refers to physical, social, and emotional areas 
of development and are discussed with themes such as quality of life, social participation, identity, independence, leadership, self-efficacy, team skills, and adventure/exploration (American Camp Association, 2005; Buskirk-Cohen, 2015; Dworken, 2001; Garst et al., 2011; Halsall et al., 2016; Hanscom, 2014; Henderson, 2012; Henderson et al., 2007; Snider \& Farmer, 2017; Zarrett et al., 2013).

Disability is defined as "a physical, mental, cognitive, or developmental condition that impairs, interferes with, or limits a person's ability to engage in certain tasks or actions or participate in typical daily activities and interactions" (The Merriam-Webster.com Dictionary).

Inclusion refers to the act or practice of including individuals with disabilities with the general population.

Accessible describes "a site building, facility, or portion thereof that complies with the Americans with Disabilities Act Standards" (U.S. Access Board, 2010). For this project, accessibility refers to the degree in which all individuals can use and/or access: environments, programs, activities, experiences, facilities, bathrooms, doorways, trails, seating, parking, and the various aspects of outdoor recreation. This list is not exhaustive and is intended to include any potential outdoor recreation or camp areas and programs.

\section{Assumptions, Limitations, and Delimitations}

\section{Assumptions}

The primary assumption is that the planned residential summer camp in Southern California will be operating in the summer of 2020 for the implementation of this project. It is also assumed that by creating more inclusive and accessible camp programming, facilities, and activities, all campers have the opportunity to benefit. This assumption is concurrent with the understanding provided by a review of the literature that indicates positive outcomes associated 
with inclusive experiences (Boyd et al., 2008; Devine et al., 2015; Papaioannou et al., 2013; Siperstein et al., 2009a; Siperstein et al., 2009b). Another assumption is that camp staff is willing to address any current limitations with the facilities and programming. Additionally, this project assumes that camp staff will be open to recommendations, adaptations, and modifications and that camp staff will also benefit from improved knowledge of OT principles.

\section{Limitations}

The population of children and adolescents attending the residential summer camp is a limitation as it is a variable outside the bounds of this project. There is no determination as to what percentage of the camp population may or may not have disabilities, or if disabilities will be relayed to camp staff prior to campers attending. This project will also occur within the current programs and facilities offered by the residential camp, and thus only these activities will be analyzed. Lastly, this project and any potential recommendations, adaptations, and modifications are confined by the funding and budget of the residential camp.

\section{Delimitation}

The scope of this project includes a residential summer camp that is open to children and adolescents of all abilities and makes no point of marketing to those with disabilities. Pathfinder Ranch can be considered a general population residential summer camp. This project is delimited in that the type of programming is both residential and occurring during summer months as compared to a year-round camp or a day camp.

\section{Chapter 2: Literature Review}

A combined and varied search of databases discussing youth and development, camps and outdoor recreation, children with disabilities, physical environments and occupational 
performance, and occupational therapy yielded literature that informs one to the current state of the proposed topic. A review of literature undercovers a handful of themes that provide insight and understanding. There is significant evidence and support for the benefits of camp experiences on PYD in both populations of children with and without disabilities. The literature also lends support for the importance of considering physical environments and inclusion to best promote occupational performance. While these themes are thoroughly understood within the context of this proposed project, the current literature discussing how occupational therapy principles and services have been researched in camp settings is limited. Further insight into the role of occupational therapy in promoting PYD through considerations of physical environments and inclusion in camp settings aims to contribute to this limited area of study. This application of occupational therapy principles can best be synthesized and understood through the EHP model which understands the collaborative interactions of person, environment, context, and occupational performance.

\section{Positive Youth Development and Camp Experiences}

Positive youth development (PYD) describes the various physical, social, and emotional areas of adolescent development that are further understood through several themes described in the literature. The comprehensive body of literature relating to PYD and camps informs a reader to the domains of development that youth have the most benefits. These domains include a blend of physical, social, and emotional areas of development and are discussed with themes such as quality of life, social participation, identity, independence, leadership, self-efficacy, team skills, and adventure/exploration (American Camp Association, 2005; Buskirk-Cohen, 2015; Dworken, 2001; Garst et al., 2011; Halsall et al., 2016; Hanscom, 2014; Henderson, 2012; Henderson et al., 2007; Snider \& Farmer, 2017; Zarrett et al., 2013). The most thorough review of youth 
development and the camp experience compiles data from 5000 campers at 80 camps across the United States and was developed by the American Camp Association (2005). This research provides a foundation for connecting PYD to the camp experience, and several researchers built upon this initial study to inform their own understanding (Buskirk-Cohen, 2015; Garst et al., 2011; Halsall et al., 2016; Hanscom, 2014; Henderson, 2012; Henderson et al., 2007; Snider \& Farmer, 2017; Zarrett et al., 2013).

\section{Quality of Life and Social Participation}

A pattern of PYD themes begin to emerge as more researchers breakdown the relationship between youth development and camps. Resounding evidence points to the benefits of camp experiences on quality of life (American Camp Association, 2005; Clark \& Nwokah, 2011; Devine et al., 2015; Garst et al., 2011; Hanscom, 2014; Henderson et al., 2007). While quality of life is broad as a variable, the researchers further delve into individual factors that encompass quality of life as a whole. Furthermore, a strong point in the literature discussing PYD and camps is the tendency to follow up with participants to determine the lasting impacts of the camp experiences as time passes (American Camp Association, 2005; Devine et al., 2015; Garst et al., 2011; Halsall et al., 2016; Snider \& Farmer, 2017). The determination that benefits of the camp experience are sustained and long-lasting further strengthens their value and importance and reiterates the need to grant these opportunities to an inclusive population of youth of all abilities.

Within the domain of PYD, several researchers determined peer relationships and social participation to be among the most positive outcome associated with camp experiences (American Camp Association, 2005; Boyd et al., 2008; Buskirk-Cohen, 2015; Clark \& Nwokah, 2011; Devine et al., 2015; Dworken, 2001; Flynn, et al., 2019; Garst et al., 2011; Goodwin et al., 
2011; Hanscom, 2014; Henderson, 2012; Henderson et al., 2007; McCarthy, 2015; Moola et al., 2014; Siperstein et al., 2009a; Siperstein et al., 2009b). While each study reviewed social participation as a PYD measure, individual factors such as peer bonding, making friends, and "social skills" were amongst the most commonly looked at in terms of social participation. The overwhelming body of literature supporting social participation benefits for those youth engaging in camp experiences cannot be denied. Peer relationships and social participation proved to have the strongest backing in terms of PYD and camp experiences, with several bodies of research providing evidence of the benefits (American Camp Association, 2005; Boyd et al., 2008; Buskirk-Cohen, 2015; Clark \& Nwokah, 2011; Devine et al., 2015; Dworken, 2001; Flynn et al., 2019; Garst et al., 2011; Goodwin et al., 2011; Hanscom, 2014; Henderson, 2012; Henderson et al., 2007; McCarthy, 2015; Moola et al., 2014; Siperstein et al., 2009a; Siperstein et al., 2009b). As these benefits of the camp experience are understood, the value of promoting these experiences for youth of all abilities is further validated. The EHP model applies OT principles to address the importance of environment and context on individuals and their occupational performance. This use of the EHP model within the camp setting helps to support how occupational therapy is an ideal mechanism for considering the role of environment and context in creating these PYD opportunities.

\section{Identity, Independence, and Leadership}

Quality of life and social participation yielded the most discussion in the literature on PYD and camp experiences. However, other aspects of youth development including selfidentity, independence, leadership, and spirituality also proved to be contributing variables of PYD (American Camp Association, 2005; Clark \& Nwokah, 2011; Goodwin et al., 2011; Halsall et al., 2016; Henderson et al., 2007). Other researchers found that physical skills are another 
positive trait that is enhanced by youths engaging in camp experiences (Clark \& Nwokah, 2011; Hanscom, 2014; Henderson et al., 2007; Siperstein et al., 2009b). Several authors drew conclusions from their findings that point to these other factors, and ultimately the value of these skills ranks as highly in terms of PYD as quality of life and social participation. These other variables help to build a well-balanced and comprehensive understanding of just how many domains the camp experience can be influential on. A reader is able to understand the importance of taking a multifocal approach to youth development across physical, social, and emotional domains of development. As occupational therapy encompasses each of these domains within its scope of practice, these findings further connect the role of occupational therapy to the camp experience and assert the significance of applying occupational therapy principles within this setting.

\section{Camp Experiences for Children with Disabilities}

Among the several articles providing evidence for PYD and camp experiences, many made no mention of children with disabilities. However, there was a large contribution of research that specifically discussed children with disabilities and their camp experiences (Bandino et al., 2014; Clark \& Nwokah, 2011; Devine et al., 2015; Flynn et al., 2019; Furtado et al., 2017; Goodwin et al., 2011; McCarthy, 2015; Moola et al., 2014). The variables discussed in both the body of literature not mentioning disabilities and those that specifically mention disabilities were fairly consistent. Benefits in peer relationships, social participation, quality of life, and related aspects of PYD were found to be just as prevalent in these studies (Bandino et al., 2014; Clark \& Nwokah, 2011; Devine et al., 2015; Flynn et al., 2019; Furtado et al., 2017; Goodwin et al., 2011; McCarthy, 2015; Moola et al., 2014). Additional themes were found in the disability-specific research including connectedness and a sense of community (Goodwin et al., 
2011; McCarthy, 2015; Moola et al., 2014). Overall, the evidence amongst both bodies of research points to similar PYD themes, indicating that children with and without disabilities benefit similarly from camp and outdoor experiences. This finding allows one to further understand the importance of providing camp experiences that are inclusive of youth and adolescents of all abilities. It also strengthens the argument that occupational therapy can have a role in ensuring that PYD expands to children of all ability levels, especially when applying the EHP model to focus on the relationship of individual, environment, context, and occupational performance.

\section{Inclusion in Camps and Outdoor Recreation}

A discussion of how occupational therapy can contribute to the enhancement of camp experiences for children of all abilities wouldn't be complete without insight into inclusion in camps and outdoor recreation. Similar concepts of PYD are discussed among the literature including how inclusive environments provide opportunities for peer relationships and social participation to occur, how inclusion can increase disability awareness that bridges gaps among youth, and how certain camp programs are providing a structure for improving inclusion (Boyd et al., 2008; Devine et al., 2015; Papaioannou et al., 2013; Siperstein et al., 2009a; Siperstein et al., 2009b). A point of emphasis among the literature are the benefits of inclusive experiences for both children with disabilities and children without disabilities. Boyd et al. (2008), Devine et al. (2015), and Papaioannou et al. (2013) determined that inclusive environments can create equal status, promote social acceptance, and increase the likelihood of peer relationships among youth of all abilities. In two 2009 studies, authors discuss how specific programming can provide the physical environment and structure to maximize these PYD benefits in camp settings (Siperstein et al., 2009a; Siperstein et al., 2009b). This literature provides support for the use of the EHP 
model to consider environment and context and its impact on an individual and subsequently their occupation performance. This occupational therapy scope of practice through the EHP model can be beneficial in creating and promoting camp and outdoor environments that best facilitate PYD.

\section{Physical Environments and Occupational Performance}

The body of research highlighting the relationship between physical environments and occupational performance is both extensive and thoroughly discussed. By narrowing the focus to determine the relationship between occupational performance and natural outdoor environments, one can begin to further delve into this topic in regard to summer camps and the potential role of occupational therapy. Several articles discuss how considering occupational performance in natural environments and outdoor recreation can have beneficial outcomes for youth development (Barakat et al., 2018; Cosco \& Moore, 2009; Marshall et al., 2016; Pfeiffer et al., 2017). Within this discussion, researchers pointed to the benefits of outdoor environments on sensory processing and participation in Activities of Daily Living (ADLs) for those on the autism spectrum and with sensory processing disorders. Variables that this research considered were stress reduction, sense of well-being, relief of physical symptoms, and enabling participation (Barakat et al., 2018; Pfeiffer et al., 2017). The understanding is that the physical environment has impacts on occupational performance, and that outdoor activities, either structured or unstructured, contribute to an environment that benefits occupational performance. Further research looks at the consideration of the physical environment on occupational performance and the benefits that are possible (Cosco \& Moore, 2009; Marshall et al., 2016). These articles provide a review of the beneficial outcomes of outdoor experiences and environments with recommendations for therapeutic structuring and adaptations. The material discussed by this 
literature is inherent in the EHP model and further supports the use of the EHP model when considering the physical environment of a residential summer camp, and how best to promote occupational performance in this setting. By discussing inclusivity, accessibility, adaptations, and design, one can continue to understand occupational therapy's role within summer camps.

\section{Camps and Occupational Therapy}

A review of the literature in regard to the current role of occupational therapy in summer camps determined a significant need for further research. Moderow and Tollefson (2018) discussed the current state of summer camps with occupational therapy services in their capstone project analyzing the perspective of counselors on occupational therapy at a residential camp for children with disabilities. Tirabassi (2017) also utilizes an occupational therapy perspective to discuss the role of environment on youth development in the camp setting. These projects both highlight and provide an agreeable consensus that the existing literature focusing on occupational therapy services and principles in camp settings is limited (Moderow \& Tollefson, 2018; Tirabassi, 2017).

Candler (2003) discussed the role of occupational therapy in a therapeutic horseback riding camp. This article provides insight into how occupational therapists can structure, adapt, modify, and contribute to the environment to enhance participation and performance in children with sensory processing disorders (Candler. 2003). While this article helps to understand the effectiveness of an occupational therapy perspective on the camp experience, it is limited in its scope by the application of sensory integration to horseback riding as a specific topic.

One of the leading proponents of occupational therapy's role in outdoor experiences and camps today is Angela Hanscom. In 2014, Hanscom published her research detailing how TimberNook, her summer camp program based on occupational therapy principles, addresses 
youth development through the role of OT. Hanscom (2014) sheds light on the decline of play, the increase in childhood obesity, and the need for preventative wellness programs that stimulate and strengthen the minds and bodies of children. Some areas of youth development looked at in her research include the enhancement of sensory development, motor development, socialemotional development, creativity, attention, and play (Hanscom, 2014). This research lays the foundation for the role of occupational therapy in summer camps and provides insight into how this role can continue to expand and apply across a variety of summer camp settings.

\section{Literature Review Conclusion}

While there was determined to be a fairly significant discussion of camp programs, the camp experience, and youth development, the gaps in connecting these topics to children with disabilities through occupational therapy principles became evident. Certain themes emerged in the literature that further emphasize the importance and value of applying an occupational therapy approach to outdoor recreation and summer camps. Several articles discussed positive youth development and camp experiences. Others informed readers to the positives related specifically for children with disabilities. Further research determined that inclusion in camps and outdoor recreation positively impacted children and youth of all ability levels. Additional literature looking at physical environments and occupational performance determined the importance of considering the relationship between these variables. Lastly, the current role of occupational therapy in summer camps and outdoor recreation was reviewed and determined that further research is needed to inform this area of practice. This combined literature search provides insight into the role that OT can take in supporting summer camps and outdoor recreation. It also contributes to the belief that an occupational therapist's role is beneficial for considering inclusivity, camp experiences, and youth development. 


\section{Chapter 3: Methods}

The initial aims and plans to complete this project proposal and program development at Pathfinder Ranch in the summer of 2020 were unfortunately derailed due to the global COVID19 pandemic. Pathfinder Ranch, along with several other entities across the world, decided to close camp and cancel their programs as a precautionary measure and reaction to the mandate of the Center for Disease Control. While this capstone project was unable to be implemented in the intended manner to fulfil the proposed project objectives, revised objectives were created that aimed to continue addressing the topics of OT, outdoor recreation, summer camps, accessibility, and inclusion. Each area of consideration is within the scope of OT including analysis of activities, environments, contexts, and occupational performance. These revised objectives draw from the thorough literature review previously described. The established themes of positive youth development, camp experiences, inclusion in camps and outdoor recreation, physical environments and occupational performance, and OT roles in camps contributed to the process of revision. Revised objectives were further determined through collaboration with the University project advisors and Elizabeth “Otter” Hueter-Willoughby, Program Director at Pathfinder Ranch. New objectives include assessing the roles of OT in the outdoors and summer camps, analyzing program needs and outdoor recreation/camp activity adaptations, researching standards, guidelines, and best practice for inclusive and accessible outdoor recreation and camps, and researching fundraising and grant options for these programs.

These revised objectives served as the foundation for the deliverable content of this project, Access Outdoors Occupational Therapy (www.accessoutdoorsOT.com). This website applies OT principles, practice, and scope to further advocate, support, and inform on topics of inclusion and accessibility within outdoor recreation and camps. The creation of a website as the 
primary deliverable content for this project developed through much consideration. Continued thought and feedback on how to reach the widest audience, what were the most effective ways to disseminate this information, and how outdoor recreation and camp programs can be best served led the website creation. Ultimately, the dissemination tactic transitioned from the idea of a guide, to that of a website, which further emphasizes the degree of development that precluded the deliverable method. A website presented the best opportunity to fulfil the revised project objectives, reach the widest audience, effectively communicate information, and continually develop and grow the concepts of Access Outdoors Occupational Therapy.

\section{Revised Project Objectives}

I. Develop an understanding of the current roles OT has in outdoor settings and camp programs

II. Review current inclusion and accessibility organizations and trainings designed for outdoor recreation and camp staff

III. Develop an understanding and synthesis of the Americans with Disabilities Act (ADA) guidelines, universal design principles, and accessibility standards for outdoor recreation, camps and facilities, and how these are put in practice

IV. Review, understand, synthesize, and promote the process for programs to apply for inclusion and accessibility fundraising and grant opportunities

V. Develop an understanding of outdoor recreation and camp programs and facilities, as well as perceptions, experiences, and input regarding inclusion, accessibility, and areas of need

VI. Develop an understanding of outdoor activity adaptations and gear available for outdoor recreation and camp programs 
VII. Synthesize research, resources and collaborations to create a website utilizing an OT scope for addressing inclusion and accessibility in outdoor recreation and camp programs

VIII. Review and discuss strategies, recommendations, and/or plans for implementing the resources and information from the website to address needs and potential adaptations that benefit outdoor recreation and camp programs

IX. Advocate for and communicate the role of OT in optimizing inclusion and accessibility to better promote occupational participation and performance in outdoor recreation and camp programs

These revised objectives reflect the opportunity to enhance the participation, experience, and accessibility of outdoor recreation and camp programs by implementing an OT perspective. The understood benefits of the outdoors and camp experiences have been discussed thoroughly and this project hopes to maximize these benefits for populations of all abilities through considerations of inclusion, accessibility, and the roles of an occupational therapist. Furthermore, this project seeks to add value and merit to the role of OT in considering environment, inclusion, and accessibility, and in youth and adolescent development in the outdoors and camp settings.

\section{Conceptual Framework}

A conceptual framework has been developed through the use of a logic model to further understand the various components and interactions within the project. See Appendix A for a full representation of the logic model applied to this project.

\section{Timeline}

The timeline below outlines the stages of development throughout the implementation of 
this project, with respect to the necessary revisions and changes that occurred as development continued.

\begin{tabular}{|c|c|}
\hline Dates & Project Development \\
\hline March 2020 - April 2020 & $\begin{array}{l}\text { - Cancellation of Pathfinder Ranch } \\
\text { experience } \\
\text { - Determining potential revision ideas } \\
\text { - Collaborations and revisions of project } \\
\text { objectives }\end{array}$ \\
\hline April 2020 - May 2020 & $\begin{array}{l}\text { - Research, review, analysis, and } \\
\text { synthesis of vast source materials } \\
\text { relating to revised project objectives } \\
\text { - Brainstorming, feedback, and } \\
\text { development of project deliverable } \\
\text { ideas }\end{array}$ \\
\hline May 2020 - June 2020 & $\begin{array}{l}\text { - Continued review and synthesis of } \\
\text { material related to objectives } \\
\text { - Attendance to relevant Move United } \\
\text { Conference presentations (virtual) } \\
\text { - Outdoor recreation activity analysis } \\
\text { - Initial contact of organizations and } \\
\text { individuals within the communities } \\
\text { addressed by project }\end{array}$ \\
\hline June 2020 - July 2020 & $\begin{array}{l}\text { Determination of resources and } \\
\text { information to include in deliverable } \\
\text { - Collaboration with individuals who } \\
\text { have experience in related project } \\
\text { areas and areas related to project } \\
\text { objectives } \\
\text { - Initial creation of website, Access } \\
\text { Outdoors Occupational Therapy, as } \\
\text { deliverable content }\end{array}$ \\
\hline July 2020 - August 2020 & $\begin{array}{l}\text { Development of website pages and } \\
\text { content as related to revised project } \\
\text { objectives } \\
\text { - Continued collaboration with those } \\
\text { aligned with project objectives } \\
\text { - Application for website publishing } \\
\text { grant through University } \\
\text { Development of envisioned next steps } \\
\text { and sustainability plan }\end{array}$ \\
\hline
\end{tabular}




\begin{tabular}{|c|c|}
\hline & - Acceptance of publishing grant \\
\hline August 2020 - Future & $\begin{array}{l}\text { Purchase of website domain } \\
\text { www.accessoutdoorsOT.com } \\
\text { - } \text { Publishing of website } \\
\text { regular blog posts, shared articles, and } \\
\text { spotlight features } \\
\text { - Further collaborations with those in } \\
\text { the communities relating to project } \\
\text { objectives } \\
\text { - Community partnership with like- } \\
\text { minded organizations } \\
\text { - Events, advocacy efforts, and } \\
\text { consultation services } \\
\text { Follow through of sustainability plan }\end{array}$ \\
\hline
\end{tabular}

\section{Chapter 4: Results}

As previously stated, the revision of project objectives precluded each step of further project development leading to the end results of the development and creation of Access Outdoors Occupational Therapy and the website (www.accessoutdoorsOT.com). Initial revisions to the project objectives were made by applying an OT perspective to the concepts discussed throughout- inclusion and accessibility in outdoor recreation and camp programs. Once new objectives were developed, further consulting with project advisors led to the finalization of these objectives, and the initial stages of thoughts on creating a resource to address these objectives began. Early brainstorming included the possibility of creating a guide to present this information and resources for outdoor recreation and camp program staff. After further consideration about reaching larger audiences, having a platform for organizing the information, and being able to keep this project updated, a website was ultimately decided as the best deliverable.

Several hours were spent researching, reviewing, analyzing, synthesizing, and either 
including or excluding resources, information, and organizations related to each project objective. As these developments continued, determination was made to provide the most relevant information and resources for each related objective. Information and resources provided by Access Outdoors Occupational Therapy aim to address project objectives, improve inclusion and accessibility understanding for outdoor recreation and camp programs, and further advocate and support the communities within these populations. These considerations led to the development of pages on the Access Outdoors Occupational Therapy website relating to project objectives. The overall function of the site aides in fulfilling the project objectives: "synthesize research, resources and collaboration with contacts to create a website utilizing an OT scope for addressing inclusion and accessibility in outdoor recreation and camp programs," "review and discuss strategies, recommendations, and/or plans for implementing the resources and information from the website to address needs and potential adaptations that benefit outdoor recreation and camp programs," and "advocate for and communicate the role of OT in optimizing inclusion and accessibility to better promote occupational participation and performance in outdoor recreation and camp programs."

\section{Website Content}

\section{Home and About Pages}

These pages were created with the intent to greet and further inform the visitor about the sites purposes. The "Home" page includes visually appealing outdoor images, with a brief description of the site's function and links to the "About" page as well as other pages of the site. The "About" page further details the contents of the site, with descriptions including “Overview," "Scope," "Significance," and "Why OT?" These pages align the visitor with the themes presented throughout this paper, and provide purpose, significance, and understanding to 
the value, mission, and vision of Access Outdoors Occupational Therapy.

\section{OT \& the Outdoors}

The "OT \& the Outdoors" page is composed of three sections: "Application of OT Foundations," "Childhood \& Adolescent Development," and "Camps, Outdoors, Nature \& OT." “Applications of OT Foundations" includes descriptions of OT models that can be useful for further understanding ways of viewing outdoor recreation and camp programs from an OT perspective. The Ecology of Human Performance (EHP), Person-Environment-OccupationPerformance (PEOP), and Model of Human Occupation (MOHO) are included. These models can help shape the way individuals view the relationships between environment, context, motivation, and occupational performance. Applying these foundational aspects of OT understanding also helps support and define the roles of OT in the improvement of inclusion and accessibility practices in the outdoor and camp settings to best promote occupational performance for individuals of all abilities. Providing additional insight into OT roles in these settings is the page section of "Childhood \& Adolescent Development." This section breaks down activities in the outdoors and nature that target areas of motor, sensory. and socialemotional development. These areas of childhood and adolescent development are most commonly targeted by current OT services in the outdoors and camps. "Camps, Outdoors, Nature, \& OT" provides links to occupational therapy practices that offer services in camps and/or outdoor settings. These organizations define the current roles of OT in the outdoors and camps and provide additional insight into how OTs can work in these settings. The inclusion of this material was largely influenced by the review of current roles of OT in the outdoor and camp settings, and in satisfying the project objective "develop an understanding of the current roles OT has in outdoor settings and camp programs." 
Collaborative efforts with OTs that work in these settings also aided in the process of website content development. Angela Hanscom, OTR/L, Founder of TimberNook and author of Balanced and Barefoot: How Unrestricted Outdoor Play Makes for Strong, Confident, and Capable Children (2016) was contacted, and provided valuable insight relating to her years of experience working on the frontlines as an occupational therapist in the outdoors, camps and nature. Additional information and insight was gained from a dialogue with another occupational therapist that works with pediatric clients in the outdoors extensively, who chose to remain anonymous. These collaborations, along with the several hours spent researching and reviewing OT roles in the outdoors and camp settings, were used to create the "OT \& the Outdoors" page as it relates to the aligning project objectives.

\section{Inclusion \& Accessibility Organizations}

The "Inclusion \& Accessibility Organizations" page informs the visitor on the leading organizations that address inclusion and accessibility as it relates to the outdoors and camp settings. The insights provided on this page aim to accomplish the project objective "review current inclusion and accessibility organizations and trainings designed for outdoor recreation and camp staff." This page, and others, were partially developed through collaboration with Elizabeth “Otter” Hueter-Willoughby, Program Director at Pathfinder Ranch, on potential areas of development for inclusive and accessible practices at Pathfinder Ranch, a residential summer camp. This much appreciated insight contributes to the fulfilment of the project objective “develop an understanding of outdoor recreation and camp programs and facilities, as well as perceptions, experiences, and input regarding inclusion, accessibility, and areas of need." Resources provided by this page include inclusion organizations, staff trainings, program evaluations, adapted outdoor recreation organizations, inclusive camp practices, and more. 
Visitors will also find guides to inclusive outdoor programing, adaptive hiking programs, engaging communities for inclusion, and including youths with disabilities. The information included on this page was done so following a thorough review and synthesis of organizations relating to the project objective. Featured organizations were chosen for their close alignment with project objectives. Aron Hall, Director of Education and Training at the National Inclusion Project aided in the development of content relating to this page. Additionally, dialogue relating to this project's scope was used in a blog posting to further spotlight National Inclusion Project and aid in the development of the website as a whole. Michelle Cook, Accessibility Program Manager at the National Center on Accessibility also provided insights into accessibility and the outdoors. The National Center on Accessibility offers a wide range of services to meet the accessibility needs of parks, outdoors, and recreation programs. Further information was provided through virtual attendance of the 2020 Move United Annual Conference. Move United, a national adaptive athletics organization, is a premiere resource for individuals, organizations, and programs hoping to learn more and develop their inclusive and accessibility practices. These collaborative efforts from both organizations that aim to improve inclusion and accessibility, and outdoor camp settings that seek to improve their programs inclusion and accessibility demonstrates the opportunity for prospective OT roles in these settings. By creating a website to function as a resource for bridging the gap between these two types of organizations, the value and understanding of an occupational therapy role to advocate, support, and address inclusion and accessibility is developed.

\section{Activity Adaptations \& Adaptive Equipment}

The "Activity Adaptations \& Adaptive Equipment" page was created to satisfy the project objective "develop an understanding of outdoor activity adaptations and gear available 
for outdoor recreation and camp programs.” This page outlines and describes common adaptations for a variety of outdoor recreation and camp program activities such as paddling, climbing, hiking, swimming, archery, horseback riding, camping, rifling and fishing. Many organizations provide detailed information about specific adaptations, strategies, and methods for improving accessibility and inclusion with these activities. This page also provides resources for adaptive equipment and links to experts in the field of adaptive activities and athletics. Move United, U.S. Adaptive, and Challenged Athletes are currently the featured adaptive athletics organizations on this page, among many others. These organizations are optimal resources for anyone considering adaptations to outdoor recreation activities and common outdoor camp programming. Additionally, these organizations offer regional and community resources and partnerships that specific programs can benefit from in developing and designing adaptive, inclusive, and accessible program activities. Companies that support inclusion and accessibility in the outdoors by developing and selling adaptive gear and equipment are also mentioned throughout this page. Providing information about these activities, adaptations, retailers and organizations demonstrates the value of Access Outdoors Occupational Therapy in promoting inclusion and accessibility in outdoor recreation and camp programs, and further supports the role of OT in these settings.

\section{Accessibility Standards \& Guidelines}

There are several documents available to the public that contribute to the understanding, implementation, and maintenance of inclusive and accessible practices for outdoor recreation and camp programs. The "Accessibility Standards \& Guidelines" page outlines, describes and links to these documents covering several aspects of outdoor and camp program considerations including facilities requirements, trail access, and parking. This page was created in fulfilment of 
the project objective "develop an understanding and synthesis of the Americans with Disabilities Act (ADA) guidelines, universal design principles, and accessibility standards for outdoor recreation, camps and facilities, and how these are put in practice." Featured on this page are resources provided by the U.S. Access Board, which includes the ADA and Architectural Barriers Act (ABA) Standards, guides to understanding these standards, and applications of these standards to federal outdoor areas. Revisions to these documents in 2013 added requirements for several types of outdoor recreation including swimming pools, boating facilities, play areas, sports facilities, trails, picnic and camping facilities, viewing areas, and beach access routes. Further insight into accessibility standards and guidelines is provided by the description and references to the U.S. Department of Agriculture (USDA) Forest Service documents, which include the Accessibility Guidebook for Outdoor Recreation and Trails. Within these documents, individuals will find detailed information about the Forest Service Outdoor Recreation Accessibility Guidelines (FSORAG) and the Forest Service Trail Accessibility Guidelines (FSTAG). The Standards provided by both the U.S. Access Board and USDA Forest Service should be considered the minimum requirements when considering inclusive and accessible facilities and programs. Insight is also provided by the National Park Service and their accessibility efforts outlined throughout All In! Accessibility in the National Park Service 20152020. Further information on this page is available that includes facilities accessibility checklists, parking and transportation, and more. These resources are inherently valuable to any outdoor recreation and camp program that seeks to evaluate, understand, and address their inclusion and accessibility. Organizing, synthesizing, and providing this information further contributes to roles that occupational therapy has in regard to these settings. 


\section{Fundraising \& Grants}

Elizabeth, director of Pathfinder Ranch, identified funding as one of the major barriers to inclusive and accessible program development for outdoor recreation and camp programs. This insight led to the creation of the "Fundraising \& Grants" page to satisfy the project objective "review, understand, synthesize, and promote the process for programs to apply for inclusion and accessibility fundraising and grant opportunities." This "Fundraising \& Grants" page identifies, describes, and provides links to foundations and organizations that support funding for inclusive and/or accessible program development. Foundations currently included on this page are The Christopher and Dana Reeves Foundation, The Tommy Wilson Memorial Grant, GoHawkeye, and The Craig. H. Neilsen Foundation, along with several funding opportunities listed through Move United. This page directly connects those who work in outdoor recreation and camp programs to available funding sources, an identified need by those within the community. By developing this page as part of a larger website addressing inclusion and accessibility in the outdoors and camps, further value is added to the roles occupational therapy has in these settings.

\section{Research \& Literature}

The development of content for this website was done so through extensive research, review, and collaboration on a range of topics. The "Research \& Literature" page provides information and links to some of the available reading that contributed to the development of this project, and the website Access Outdoors Occupational Therapy. The "Research \& Literature" page is currently divided into "Outdoor Play," "Positive Youth Development \& Camp Experiences," "Inclusion in Camp Settings," and "Outdoor Environments \& Occupational Performance." This information is included for visitors who seek additional insight relating to the content material provided by the website and as an advocacy effort for expanding knowledge 
on related topics.

\section{Blog}

The "Blog" page was created as an avenue to regularly update the site, provide deeper insight into related topics, share spotlight collaborations, and more. A blog page allows for continued additions to the site and aims to satisfy the project objective "advocate for and communicate the role of OT in optimizing inclusion and accessibility to better promote occupational participation and performance in outdoor recreation and camp programs." Current blog entries include a discussion of environment and occupational performance, a spotlight on National Inclusion Project, and ideas for outdoor play activities. As the site continues to grow, the blog page will be utilized for further collaborations and detailed insights relating to outdoor recreation, camp programs, inclusion, accessibility, and the roles of OT in these settings.

\section{Contact}

The "Contact" page provides an opportunity for visitors to reach out, give feedback, share ideas, ask questions, or request additional content considerations. Access Outdoors Occupational Therapy aims to provide resources and information for outdoor recreation and camp programs, and occupational therapists interested in these settings. By offering ways to encourage feedback, the website can continue to grow and develop with the best interests of the visitors. Further collaboration and community partnership are also prospective development areas that can be achieved by providing the "Contact" page.

\section{Acknowledgements, Copyright, Disclaimer}

This page was created to acknowledge the individuals and organizations that helped contribute to the development of this project and website. Additional information about Access Outdoors Occupational Therapy, affiliation with other organizations, copyright law, and use of 
content is also provided. A disclaimer also informs the visitor that the use of this website is for informational purposes, and that the content of the website is provided on an "as is" basis.

\section{Results Conclusion}

The end results of the development of a website, Access Outdoors Occupational Therapy, was a multifaceted approach to satisfy the revised project objectives from an OT perspective and best reach outdoor recreation and camp programs, and occupational therapists interested in these settings. Considerations were made to the material gathered throughout the project including the literature review, the research, review, and synthesize of information relating to project objectives, and collaborations and discussions with those in these communities. The aims for the website are to be continually updated and improved to best serve these communities, and to address project objectives as best suited for site visitors, including outdoor recreation and camp programs, and occupational therapists.

\section{Chapter 5: Discussion and Conclusion}

Several necessary revisions were required due to the outbreak of the COVID-19 global pandemic as this project transitioned from proposal to implementation in the spring of 2020 . While these changes ultimately impacted the proposed methods, setting, and intent of implementation with this project, the deliverable product and methods for creating this product maintain alignment with the purpose, rationale, significance, and scope of the project. The creation of Access Outdoors Occupational Therapy fulfils the intent of the project by providing a resource for outdoor recreation and camp programs, and occupational therapists in these settings. Identified roles for OT in these settings are further defined through the revised project objectives, and the content created by the Access Outdoors Occupational Therapy website. Consideration to the content provided by Access Outdoors Occupational Therapy was done through continued 
collaboration, feedback, and sharing with educators, advisors, outdoor recreation and camp staff, and occupational therapists as previously discussed throughout. The understandings and insights provided by these collaborations, combined with the thorough research, review, and synthesis of literature and resources relating to project objectives contributed to the development of Access Outdoors Occupational Therapy. There are several organizations and individuals that are involved in the communities addressed by this project. While Access Outdoors Occupational Therapy features those most closely aligned with project objectives, the possibilities for expansion, collaboration, and partnership are areas of further site sustainability, development, and growth. A 12-month publishing plan to launch Access Outdoors Occupational Therapy was made possible by an accepted scholarship grant through the University of St. Augustine for Health Sciences. This grant ensures that the website can grow roots within these communities, be shared by individuals from around the globe, and be made available to those who benefit from the provided information.

\section{Evaluating Website Effectiveness}

An important aspect of developing a website created to reach a wide audience, provide information for outdoor recreation and camp programs, and further expand on the roles of OT in these settings is the evaluation of the effectiveness of the website in achieving these objectives. Throughout the website, there are several areas where visitors can submit contact forms for feedback, discussion, questions, and considerations, which are all actively encouraged on the site. In addition to the website contact forms, social media accounts have been created for the website to further promote the site and reach out to the targeted audiences. This allows for direct connections with outdoor recreation and camp programs, outdoor occupational therapists, and anyone else interested in these topics. As social media continues to dominate virtual connections, 
this will be a valuable tool in receiving feedback, connecting with targeted audiences, and promoting the site and its objectives. The use of search engine optimization, site traffic data and analytics, and marketing strategies, all made available through Wix, are additional valuable resources for evaluating the site and its effectiveness. This insight includes information that is useful is adapting the website to best reach its audience such as where users are located when viewing the site, how users accessed the site, which search terms yield the most results, how long users stayed on the site, and which areas of the site users accessed. This allows for the site to grow, adapt, and develop as this information is provided on a daily basis, with the abilities to compare data between weeks and evaluate how changes impacted site traffic. Evaluating website effectiveness will also be achieved through ongoing efforts to collaborate with targeted audiences. These efforts will aim to expand on what audiences want from the website and Access Outdoors Occupational Therapy and can continue to shape the desired impacts as they relate to project objectives. The strategies mentioned above represent the continuous efforts necessary for considering and evaluating the effectiveness of the website in reaching its targeted audiences and delivering the desired impacts.

\section{Envisioned Next Steps}

This project, and Access Outdoors Occupational Therapy seek to remain updated, active, and current. There are several potential areas of future development including multimedia blog posts, featured insights and organization/individual spotlights, product and guide descriptions, community partnerships, fundraising, and charity events. Additional areas for website growth and sustainability are supported by the publishing plan purchased using the University grant funds. These include online branding and marketing, search engine optimization, and relevant digital advertising which are key features involved in driving website traffic. Access Outdoors 
Occupational Therapy aims to not only provide these communities with resources and information, but to also get involved on the ground when the risk to public health subsides and it is safe to do so. Throughout the implementation of this project, the student researcher developed knowledge and skills of inclusion and accessible practices in the outdoor and camp settings. The development of this knowledge and skills further translates into potential OT practice roles. These include staff education on topics of inclusion and accessibility, facility and program evaluations, consulting and recommendations for improving inclusion and accessibility, and partnerships to access funds for achieving these improvements. It is envisioned that Access Outdoors Occupational Therapy will continue to develop content relevant to the project objectives, the roles of OT in the outdoors and camp programs, and inclusion and accessibility in these settings.

\section{Sustainability Plan}

It is envisioned that the creation of the website, www.accessoutdoorsot.com, as an educational and informational resource in partial fulfilment of the requirement for the degree of doctor of occupational therapy is the beginning step for a continual project. Access Outdoors Occupational Therapy received a 12-month pro publishing grant through the University of St. Augustine for Health Sciences that allows the website to remain live until August 2021. This presents opportunities for developing a sustainability plan that allows for the website and ideas to progress, grow, expand, and be shared. This plan outlines the envisioned processes for ensuring this sustainability.

\section{Search Engine Optimization}

Access Outdoors Occupational Therapy was developed through the use of Wix, an online platform for creating and publishing websites and domains. The 12-month pro publishing plan 
includes access to both Wix and Google features that contribute to driving site traffic. These features allow for the website creator to optimize and grow their search engine visibility. Access Outdoors Occupational Therapy has been indexed and listed through Google, which allows searchers to access the website when browsing for related, personalized keywords such as “outdoor occupational therapy," "accessibility outdoors," "outdoor activity adaptations," and more. The use of Google Search Console allows for further understanding of the data related to site traffic through analytics of search queries, impressions, and clicks. As the website creator, this information can continually be adjusted and altered to best promote the website based on the available data and search engine optimization features. It is envisioned that continual incoming data related to search engine optimization, the site, and related searches can further drive site traffic and serve as a point of sustainable site growth over the next 12 months.

\section{Social Media \& Online Presence}

The promotion and sustainable efforts of Access Outdoors Occupational Therapy will also include expansion beyond the website domain and site pages. Social media accounts with the same handle "Access Outdoors Occupational Therapy" have been created on Instagram and Twitter. These accounts aim to further promote the site, it's purpose, and content. Additionally, these accounts aim to share related content material, promote site pages and blog posts, and connect with like-minded individuals and organizations. A further online presence will include connecting and sharing the website within related online communities and forums. The expansion of the website into other areas of online presence such as social media accounts and online forums further supports the promotion and vision of sustainable growth related to Access Outdoors Occupational Therapy. 


\section{Community Collaboration \& Partnership}

Access Outdoors Occupational Therapy was created to provide information and resources for the appropriate target audience related to content topics. This avenue was created through necessity deriving from the massive shift to online and remote work in the wake of the global pandemic occurring throughout 2020. It is intended that Access Outdoors Occupational Therapy will expand to community collaborations and partnerships, when the risk to public health subsides. This includes working with outdoor recreation programs, summer camps, community businesses, and individuals to best promote inclusion and accessibility in the most appropriate way. These potential partnerships and collaborations include facilities and activities evaluations/assessments, staff education and training, fundraising and grant writing, and individualized program recommendations. The details of these specific collaborations and partnerships remain to be seen, as they will be further identified by the specific opportunities presented, desires of the organizations, and agreed upon roles for Access Outdoors Occupational Therapy.

\section{Professional Development \& Sharing}

The knowledge and skills associated with the content related to Access Outdoors Occupational Therapy are areas of continued professional development and growth. Not only are there ample opportunities to continue learning more about the target communities and content, there are also opportunities to share what Access Outdoors Occupational Therapy brings to the table. These include potential presentations, webinars, collaborative blog posts, shared resources, and trainings. The website will also be shared with colleagues, friends, family, and those who were collaborated with throughout the development of this project. Additionally, Access Outdoors Occupational Therapy will be added to the creator's LinkedIn professional account and 
resume, further emphasizing the role as creator of this website and encouraging the continued development within the areas related to Access Outdoors Occupational Therapy.

\section{Sustainability Plan Conclusion}

The development of Access Outdoors Occupational Therapy began as a collection of ideas and was further strengthened through feedback, collaboration, research, review, and synthesis of related content materials. The publishing of the website grants significant opportunities to further develop Access Outdoors Occupational Therapy from a website through the opportunities presented throughout this sustainability plan.

\section{Occupational Therapy Impact}

The development of this project has occurred through an OT scope, providing perspective and guidance through each aspect. One aspect of this was a review of current literature and research of topics relating to OT and the outdoors and camps, physical environments and occupational performance, inclusion and accessibility, and positive youth development. Further implementation of this project reviewed current OT roles in the outdoor recreation and camp program settings, with insight from occupational therapists who have been fundamental in defining these roles. These insights contributed to the understanding that occupational therapists can utilize the outdoors, outdoor recreation, and camp programs to further support positive youth development and aid in childhood and adolescent development. Application of the OT models the Ecology of Human Performance (EHP) model, the Person - Environment - Occupation Performance (PEOP) model, and Model of Human Occupation (MOHO) were utilized and contributed to the understanding of how OT can approach inclusion and accessibility in outdoor recreation and camp programs. These foundational components of OT practice support the continued development of new OT roles relating to project objectives. Access Outdoors 
Occupational Therapy aims to continue involvement with these communities through a multitude of services. The skills and knowledge developed through this project implementation serve as a prerequisite for providing these services. Continued advocacy efforts within these communities include expanding the knowledge and promotion of inclusive and accessible environments to better support occupational performance and participation for individuals of all abilities. Collaborations with other occupational therapists, inclusion and accessibility organizations, outdoor recreation and camp programs, and others involved in these communities has been fundamental, and will continue to impact and develop the roles of OT in these settings. Potential community partnerships, presentations on project topics, continual updates to the website, and further collaborations are all possibilities created by this project and the development of Access Outdoors Occupational Therapy. The current impacts of this project on OT include a thorough review of literature pertinent to project topics, applications of foundational occupational therapy models, and insights into current OT roles in these settings. Potential impacts include expanded roles of OT services in these settings, continued advocacy with the communities involved in this project, and further research into how occupational therapists can best serve these populations.

\section{Conclusion}

Several dynamic components of positive youth and adolescent development occur when children engage in outdoor and camp experiences (Buskirk-Cohen, 2015; Dworken, 2001; Halsall et al., 2016; Hanscom, 2014; Henderson et al., 2007; Snider \& Farmer, 2017; Thurber et al., 2007; Zarrett et al., 2013). These experiences are largely influenced by factors that either aid in facilitating or hindering occupational performance and participation in these settings. Environment and context are aspects of these experiences that are highly influential (Cosco \& Moore, 2009; Furtado et al., 2017; Goodwin et al., 2011; Hanscom, 2014; Marshall et al., 2016; 
Papaioannou et al., 2013; Pfeiffer et al., 2017; Walker et al., 2010). The application of OT perspectives and foundations grants the opportunity to explore these outdoor recreation and camp experiences to identify strategies and methods for improving inclusion and accessibility practices, which further promotes occupational performance and participation for individuals of all abilities. Project objectives were developed through research, review, and synthesis of identified areas of consideration and collaborative efforts with involved members of the OT, outdoor recreation, and camp communities. These objectives are foundational components to the development of Access Outdoors Occupational Therapy, a website created to address inclusion and accessibility for outdoor recreation and camp practices from an occupational therapy perspective. The cumulation of this project through the creation of Access Outdoors Occupational Therapy reflects the insights and knowledge acquired while researching the related content material. When considering future endeavors related to this project, Access Outdoors Occupational Therapy seeks to further promote and advocate for inclusion and accessibility, establish roles for occupational therapists in the outdoor and camp settings, and work within these communities to best support inclusion and accessibility practices. These practices ultimately contribute and add to the scope of OT and intend to have lasting beneficial impacts on the involved communities. 


\section{References}

American Camp Association (2005). Directions: Youth development outcomes of the camp experience. https://www.acacamps.org/sites/default/files/resource library/reportdirections-youth-development-outcomes.pdf

American Occupational Therapy Association [AOTA]. (2017). Occupational therapy practice framework: Domain \& process. American Journal of Occupational Therapy, 68(Suppl. 1), S1-S48. http://doi.org/10.5014/ajot.2014.682006

Bandino, M. L., Garfinkle, R. A., Zickefoose, B. A., \& Hsieh, D. T. (2014). Epilepsy at a summer camp for children and young adults with developmental disabilities: A 3-year experience. Military Medicine, 179(1), 105-110. https://doi.org/10.7205/MILMED-D-13-00304

Barakat, H., Bakr, A., \& El-sayad, Z. (2018). Nature as a healer for autistic children. International Journal of Environmental Science and Sustainable Development, 42-62. https://doi.org/10.21625/essd.v3i2.277

Boyd, C., Fraiman, J., Hawkins, K., Labin, J., Sutter, M., \& Wahl, M. (2008). Effects of the STAR intervention program on interactions between campers with and without disabilities during include summer day camp activities. Education and Training in Developmental Disabilities, 43(1), 92-101. http://daddcec.org/Portals/0/CEC/Autism_Disabilities/Research/Publications/Education Training_Development_Disabilities/2008v43_Journals/ETDD_200803v43n1p092101_Effects_STAR_Intervention_Program_Interactions_Between_Campers.pdf 
Buskirk-Cohen, A. A. (2015). Effectiveness of a creative arts summer camp: Benefits of a shortterm, intensive program on children's social behaviors and relationships. Journal of Creativity in Mental Health, 10(1), 34-45. https://doi.org/10.1080/15401383.2014.946637

Candler, C. (2003). Sensory integration and therapeutic riding at summer camp. Physical \& Occupational Therapy in Pediatrics, 23(5), 51-64. https://doi.org/10.1080/ $\underline{\mathrm{J} 006 \mathrm{v} 23 \mathrm{n} 03 \_04}$

Clark, M. K., \& Nwokah, E. E. (2011). Play and learning in summer camps for children with special needs. American Journal of Play, 3(2), 238-261. https://www.journalofplay.org/sites/www.journalofplay.org/files/pdf-articles/3-2-articleplay-learning-summer-camps.pdf

Cole, M. B., \& Tufano, R. (2008). Applied theories in occupational therapy: A practical approach. SLACK.

Cosco, N. \& Moore, R. (2009). Sensory integration and contact with nature: Designing outdoor inclusive environments. The NAMTA journal, 34(2), 159-177. https://www.slideshare.net/pd81xz/zwy310

Devine, M. A., Piatt, J., \& Dawson, S. (2015). The role of a disability-specific camp in promoting social acceptance and quality of life for youth with hearing impairments. Therapeutic Recreation Journal, 49(4), 293-309. https://pdfs.semanticscholar.org/6f13/9ffa2d77b82aa4743401b89c1e2d28c769ec.pdf 
Disability. In The Merriam-Webster.com Dictionary. https://www.merriamwebster.com/dictionary/disability

Dunn, W., Brown, C., \& McGuigan, A. (1994). The Ecology of Human Performance: A framework for considering the effect of context. American Journal of Occupational Therapy, 48(7), 595-607. https://doi.org/10.5014/ajot.48.7.595

Dworken, B.S. (2001). Research reveals the assets of camp: Parents and campers give their opinions. Camping Magazine, 74(5), 40. https://www.thefreelibrary.com/Research+Reveals+the+Assets+of+Camp+Parents+and+ campers+give+their...-a080194449

Flynn, R., Ricker, A., Dolezal, C., Kunin, M., \& Mellins, C. (2019). Residential summer camp for youth with special needs: A longitudinal approach to investigating differences in social skills. Children and Youth Services Review, 96, 354-363. https://doi.org/10.1016/j.childyouth.2018.10.036

Furtado, O., Lieberman, L. J., \& Gutierrez, G. L. (2017). Sport summer camp for children and youth with visual impairment: Descriptive case study of camp abilities. British Journal of Visual Impairment, 35(2), 154-164. https://doi.org/10.1177/0264619616685374

Garst, B.A., Browne, L.P., \& Bialeschki, M.D. (2011). Youth development and the camp experience. New directions for youth development, $2011(130), 73-87$. https://doi.org/10.1002/yd.398

Goodwin, D., Lieberman, L., Johnston, K., \& Leo, J. (2011). Connecting through summer camp: Youth with visual impairments find a sense of community. Adapted Physical Activity 
Quarterly, 28(1), 40-56.

https://digitalcommons.brockport.edu/cgi/viewcontent.cgi?article $=1010 \&$ context=pes_fa cpub

Halsall, T., Kendellen, K., Bean, C., \& Forneris, T. (2016). Facilitating positive youth development through residential camp: Exploring perceived characteristics of effective camp counselors and strategies for youth engagement. Journal of Park and Recreation Administration, 34(4), 20-35. https://doi.org/10.18666/JPRA-2016-V34-I4-7273

Hanscom, A. (2014). Using occupational therapy principles in developing a nature camp for all children. Special Interest Section Quarterly, 37(4), 1-3. https://www.aota.org/ /media/Corporate/Files/Secure/Publications/SIS-QuarterlyNewsletters/SI/SISIS-Dec-2014.pdf

Hanscom, A. (2016). Balanced and barefoot: How unrestricted outdoor play makes for strong, confident, and capable children. New Harbinger Publications.

Henderson, K.A., Bialeschki, M.D., Scanlin, M.M., Thurber, C., Whitaker, L.S., \& Marsh, P.E. (2007). Components of camp experiences for positive youth development. Journal of Youth Development, 1(3), 1-12. https://doi.org/10.5195/jyd.2007.371

Henderson, K.A. (2012). Peer relationships and camps. Accredited Camp Association Briefing Papers Series. https://www.acacamps.org/sites/default/files/downloads/Briefing-Paper$\underline{\text { Peer-Relationships-Camps.pdf }}$ 
Marshall, A., Myers, C., \& Pierce, D. (2016). A century of therapeutic use of the physical environment. American Journal of Occupational Therapy, 71(1), 1-10. https://doi.org/10.5014/ajot.2017.023960

McCarthy, A. (2015). Summer camp for children and adolescents with chronic conditions. Pediatric Nursing, 41(5), 245-250. https://search.proquest.com/docview/1723665029?accountid=158603

Moderow, E., \& Tollefson, H. (2018). The perspective of counselors on occupational therapy at a residential camp for children with disabilities. Occupational Therapy Capstones, 395. https://commons.und.edu/ot-grad/395

Moola, F. J., Faulkner, G. E. J., White, L., \& Kirsh, J. A. (2014). The psychological and social impact of camp for children with chronic illnesses: A systematic review update: Camps for sick children. Child: Care, Health and Development, 40(5), 615-631. https://doi.org/10.1111/cch.12114

Our Mission. (2019). Pathfinder Ranch. http://pathfinderranch.com/

Papaioannou, C., Evaggelinou, C., Barkoukis, V., \& Block, M. (2013). Disability awareness program in a summer camp. European Journal of Adapted Physical Activity, 6(2), 19-28. https://doi.org/10.5507/euj.2013.007

Pfeiffer, B., Coster, W., Snethen, G., Derstine, M., Piller, A., \& Tucker, C. (2017). Caregivers' perspectives on the sensory environment and participation in daily activities of children with autism spectrum disorder. American Journal of Occupational Therapy, 71(4), 1-9. https://doi.org/10.5014/ajot.2017.021360 
Provident, I., \& Colmer, M. (2011). Muscular dystrophy summer camp: A case study of a nontraditional level I fieldwork using a collaborative supervision model. IOS Press, 44, 337344. https://doi.org/10.3233/WOR-121510

Siperstein, G.; Glick, G.; and Parker, R. (2009a). Social inclusion of children with intellectual disabilities in a recreational setting. Intellectual and Developmental Disabilities, 47, 97107. https://doi.org/10.1352/1934-9556-47.2.97

Siperstein, G., Pociask, S., \& Barnes, K. (2009b). Let's ALL play: Helping to make inclusion in summer camps a success. Camping Magazine, 82(6). https://www.acacamps.org/resource-library/camping-magazine/lets-all-play-helping$\underline{\text { make-inclusion-summer-camps- }}$ success\#: :text=Evidence $\% 20$ from $\% 20$ counselors $\% 20$ suggests $\% 20$ that,inclusive $\% 20$ pro gramming $\% 20$ at $\% 20$ the $\% 20$ camps.

Snider, C. L., \& Farmer, J. R. (2017). Impacts of a southern Indiana summer camp: Adult reflections on childhood experiences. Journal of Youth Development, 11(3), 175-187. https://doi.org/10.5195/JYD.2016.470

Summer Camp. (2019). Pathfinder Ranch. http://pathfinderranch.com/departments/

Tirabassi, A. (2017). The influence of the environment on the quality of social interaction among children during play (Unpublished thesis). University of New Hampshire, Durham, NH.

Thurber, C., Scanlin, M., Scheuler, L., \& Henderson, K. (2007). Youth Development Outcomes of the Camp Experience: Evidence for Multidimensional Growth. Journal of Youth and Adolescence, 36, 241-254. https://doi.org/10.1007/s10964-006-9142-6 
U.S. Access Board. (2010). DOJ's 2010 ADA standards. https://www.access-

board.gov/guidelines-and-standards/buildings-and-sites/about-the-ada-standards/ada$\underline{\text { standards/doj-s-2010-ada-standards }}$

Walker, A. N., Barry, T. D., \& Bader, S. H. (2010). Therapist and parent ratings of changes in adaptive social skills following a summer treatment camp for children with autism spectrum disorders: A preliminary study. Child \& Youth Care Forum, 39(5), 305-322. https://doi.org/10.1007/s10566-010-9110-x

Zarrett, N., Sorensen, C., \& Skiles, B. (2013). Environmental and social-motivational contextual factors related to youth physical activity: Systematic observations of summer day camps. International Journal of Behavioral Nutrition and Physical Activity, 10(63), 1-13. https://doi.org/10.1186/1479-5868-10-63 
Appendix A

LOGIC MODEL FOR ACCESS OUTDOORS OCCUPATIONAL THERAPY DEVELOPMENT

\begin{tabular}{|c|c|c|c|}
\hline PURPOSE & \multicolumn{3}{|c|}{$\begin{array}{l}\text {-Fulfil revised project objectives addressing inclusion and accessibility in the } \\
\text { outdoors and camps through an occupational therapy perspective }\end{array}$} \\
\hline CONDITIONS & \multicolumn{3}{|c|}{$\begin{array}{l}\text {-Ideas and objectives developed through the necessary revisions made in the } \\
\text { wake of the COVID-19 pandemic that altered the preliminary proposal }\end{array}$} \\
\hline INPUTS & ACTIVITIES & OUTPUTS & OUTCOMES \\
\hline $\begin{array}{ll}\text { - } & \text { Student } \\
\text { researcher } \\
\text { - } & \text { Literature, } \\
\text { programs, } \\
\text { organizations, } \\
\text { communities } \\
\text { review } \\
\text { - Collaborations } \\
\text { with advisors } \\
\text { and those in } \\
\text { related project } \\
\text { areas } \\
\text { USA website } \\
\text { publishing } \\
\text { grant }\end{array}$ & 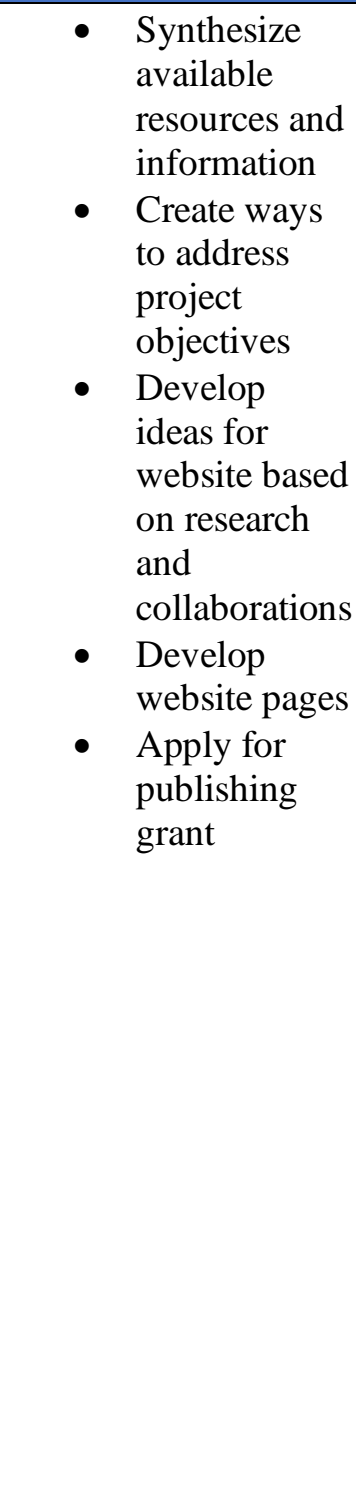 & $\begin{array}{l}\frac{\text { Access }}{\text { Outdoors }} \\
\frac{\text { Occupational }}{\text { Therapy }} \\
\text { website }\end{array}$ & $\begin{array}{l}\text { - SHORT-TERM } \\
\text {-Sharing of } \\
\text { information with } \\
\text { outdoor recreation \& } \\
\text { camp programs } \\
\text {-Increased access } \\
\text { and exposure to } \\
\text { inclusion \& } \\
\text { accessibility } \\
\text { resources } \\
\text { MID-TERM } \\
\text {-Improved } \\
\text { knowledge and use } \\
\text { of inclusion \& } \\
\text { accessibility } \\
\text { practices in outdoor } \\
\text { recreation and } \\
\text { summer camp } \\
\text { programs } \\
\text {-Further } \\
\text { development of } \\
\text { collaborative } \\
\text { resources with these } \\
\text { programs } \\
\text { LONG-TERM } \\
\text {-Community } \\
\text { partnerships with } \\
\text { related organization } \\
\text { and foundations } \\
\text {-Consulting with } \\
\text { programs to } \\
\text { implement changes }\end{array}$ \\
\hline IMPACTS & \multicolumn{3}{|c|}{$\begin{array}{l}\text {-More inclusive \& accessible outdoor recreation \& camp programs } \\
\text {-Increased knowledge of outdoor inclusion \& accessibility } \\
\text {-Expanded OT roles in these settings }\end{array}$} \\
\hline
\end{tabular}

